\title{
Notes on Advertisement Calls Playback by Three Species of Sarawakian Frogs
}

\author{
MUHAMMAD FADZIL AMRAM*11 RAMLAH ZAINUDIN ${ }^{1} \&$ HASNIZAM ABDUL WAHID $^{2}$ \\ ${ }^{1}$ Faculty of Resource Science and Technology, Universiti Malaysia Sarawak, 94300, Kota Samarahan, Sarawak, \\ Malaysia; ${ }^{2}$ Faculty of Applied and Creative Arts, Universiti Malaysia Sarawak, 94300 Kota Samarahan, \\ Sarawak, Malaysia \\ *Corresponding author: mfadz89@gmail.com \\ Received: 8 May $2020 \quad$ Accepted: 28 May $2020 \quad$ Published: 30 June 2020
}

\begin{abstract}
Male and female frogs respond differently towards advertisement calls. The fittest call will be chosen by the conspecific female to produce progenies, means that call from male to female is to ensure the survival of the species. The objective is to observe the response of both male and female frogs by playing the advertisement call to another male or female of the same species at their breeding site. The advertisement calls were recorded manually and were replayed using a speaker with built-in amplifier. The frog's responses were then recorded in video form. Ambient temperatures were taken using data logger. The calls were analyzed to describe call characteristics. From the acoustic playback, both male and female Pulchrana glandulosa responded towards the calls. The male produces a crying-like sound while approaching playback source meanwhile the female produces a small "wik" sound. Male Pulchrana baramica responded by straining their calls and approaches the playback source. For male Kurixalus appendiculatus, the individuals responded by moving towards the sound source without calling. Results show that male of different species and male and female of the same species react differently towards playback calls. This shows that the breeding call recorded can be recognized by other frogs when they were played on amplifier.
\end{abstract}

Keywords: Advertisement calls, call characteristics, playback recording, Sarawakian frogs

Copyright: This is an open access article distributed under the terms of the CC-BY-NC-SA (Creative Commons Attribution-Non Commercial-Share Alike 4.0 International License) which permits unrestricted use, distribution, and reproduction in any medium, for non-commercial purposes, provided the original work of the author(s) is properly cited.

\section{INTRODUCTION}

Advertisement calls are necessary for males and females of the same species to indicate it is time to sexually reproduce. If the call from male frogs is not recognized by female frogs, then no breeding will occur, and the species are reproductively isolated from each other. Male and female frogs respond differently towards advertisement calls. This is because the call from male to female is to ensure the survival of the species, as only the fittest will be chosen by the conspecific female to produce progenies (Zainudin et al., 2009; Zainudin et al., 2010; Amram et al., 2018). For frogs that call in choruses, the sounds of a chorus could also act as an acoustic beacon for some frogs to locate the breeding aggregation (Bee, 2007). The calls contain unique acoustic characters that allow them to communicate for reproductive receptiveness (Preininger et al., 2013; Reichert, 2013; Lima et al., 2014; Santana et al., 2016).
However, not much is known on how well they respond towards playback recording. Playbacks of audio stimuli to wild animals are a widely used experimental tool in behavioral ecology. However, most of playback experiments are constrained by observer limitations such as the time observers can be present, or the accuracy of observation (Lendvai et al., 2015). These problems are more apparent when playbacks are targeted towards specific purposes, like towards specific individuals to illicit their response. Previous field playback studies have shown that other than for mating, vocalizations also mediate species recognition among male frogs (Amézquita et al., 2005). They play an important role in sexual selection by male-male competition, like to assess opponent's resource holding potential (Bee et al., 1999; Bee et al., 2000), to mediate intermale spacing (Marshall et al., 2003), and for recognition of territorial neighbour (Bee \& Gerhardt, 2002). The calls playback was used in this study to observe the response of both male and 
female frogs by playing the advertisement calls of the species at their breeding site. It is also to see whether the recorded calls are good enough to be used in playback recording.

\section{MATERIALS AND METHODS}

\section{Studied Species}

Three species has been recorded for these studies, namely Pulchrana baramica, Pulchrana glandulosa and Kurixalus appendiculatus. Pulchrana baramica is a small to medium-sized frog that inhabits peat swamp forest (Inger \& Stuebing, 2005). Pulchrana glandulosa is similar to $P$. baramica, where they shared similar habitats. Pulchrana glandulosa is larger, with more robust appearance, and have round bumps on the flank (Inger \& Stuebing, 2005). Another species, $K$. appendiculatus is a small tree frog that lives in swampy area and in well-drained forest. During the sampling period, all three species can be heard calling and some can be found in amplexus. During those periods, nuptial pad can be observed on the ventral part of the shoulders of male $P$. glandulosa. These three species were selected for this study because they shared similar habitats, and the calls of all three species can be heard at the same time. All three species were also not overly sensitive to light, where they keep calling even when the flashlights were shone on them.

\section{Sampling Method}

The study was conducted on the $5^{\text {th }}$ to $21^{\text {st }}$ September 2015 for acoustic recording session, and $25^{\text {th }}$ to $29^{\text {th }}$ August 2016 and $11^{\text {th }}$ to $17^{\text {th }}$ October 2017 for playback recording session. The study was conducted at Nightwalk Trail, Gunung Mulu National Park (N 0403.021' E $\left.114^{\circ} 51.399^{\prime}\right)$ in Malaysian Borneo. The voice recordings were done using TASCAM DR-40 Linear PCM Recorder with sampling rate of $44.1 \mathrm{kHz}$ and bit depth of 16-bit, and recorded in stereo. The recording distance was from $30 \mathrm{~cm}$ to $3 \mathrm{~m}$. The advertisement calls recorded were in wave format. Call playback were done using speaker with builtin amplifier with frequency respond of $100 \mathrm{~Hz}-10$ $\mathrm{kHz}$ and cut-off at $\pm 3 \mathrm{~dB}$. The videos were taken using Sony DCR-SR68E Camcorder. Ambient temperature and humidity data were taken and measured using HOBO Pro V2 data logger. The recorded sounds were analyzed using Soundruler software (Gridi-Papp, 2003-2007) and Praat software.
Upon encounter with targeted frogs, playbacks of calls according to respective species were played using a speaker with USB drive containing the playbacks attached to it close to the frogs with distance from 1 to $3 \mathrm{~m}, 3$ to $5 \mathrm{~m}$ and more than $5 \mathrm{~m}$, and the responses of the frogs were observed. The playback was played for 5 to 10 minutes, depending on the reactions of the frogs. The playback was played up to 10 minutes if the targeted frogs made any responds and maximum of 5 minutes if the frogs did not make any movement. Any call produced by responding frogs were recorded using a digital recorder. The actions and movements of responsive frogs were filmed using a camcorder. The frogs were caught to obtain their measurements and weight and to determine their sex. Then the frogs were released at the exact place where they were caught. The nonresponsive individuals were also caught but not measured and weighted, to minimise the contact with the frog. All captured frogs have their belly inspected for egg in female and the absence/presence of nuptial pad in male.

\section{RESULTS}

Ambient temperature recorded at night ranges from 24.4 to $25.3{ }^{\circ} \mathrm{C}$. Results showed that both male and female of frog species react differently towards playback calls. Responses towards the playback recording in selected frog species are as the following:

\section{Acoustic Playback of $\boldsymbol{P}$. glandulosa (Rough-sided Frog)}

During acoustic playback, both male $(\mathrm{n}=10)$ and female $(\mathrm{n}=6) P$. glandulosa responded towards the calls. All male $P$. glandulosa in the radius of $5 \mathrm{~m}$ responded towards the playback call without playing the calls directly at them. Figure 1 shows the oscillogram and spectrogram of one note of normal $P$. glandulosa calls that was used for playback recording. The frequency spectrogram reveals that the notes contain an upward frequency modulation, with 8 harmonics visible. The $2^{\text {nd }}$ harmonics is the dominant frequency, with frequency of $1.4 \mathrm{kHz}$. All male $P$. glandulosa frogs that were encountered had responded to the calls by producing crying-like sound "Wraa" of a single pulse (Figure 2), with two note repetitions every 60 seconds. The frequency spectrogram reveals that there are no frequency modulations, with 6 harmonics visible. The second harmonics is the dominant frequency, with frequency of $1.3 \mathrm{kHz}$. However, it was 3rd harmonic that have longer durations. 


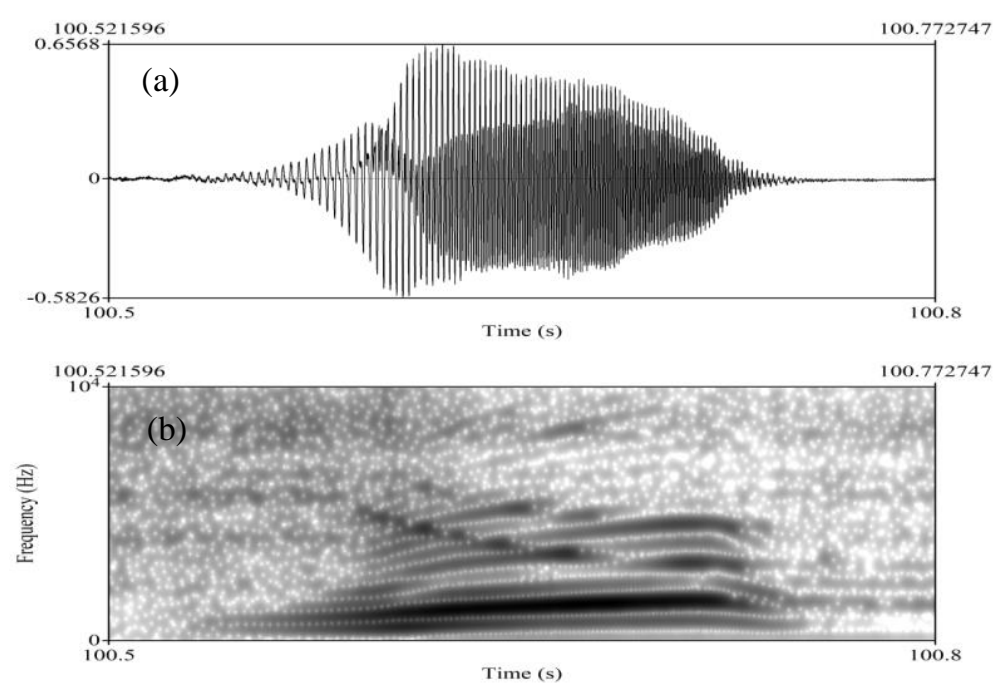

Figure 1. The (a) oscillogram and (b) spectrogram of male P. glandulosa call
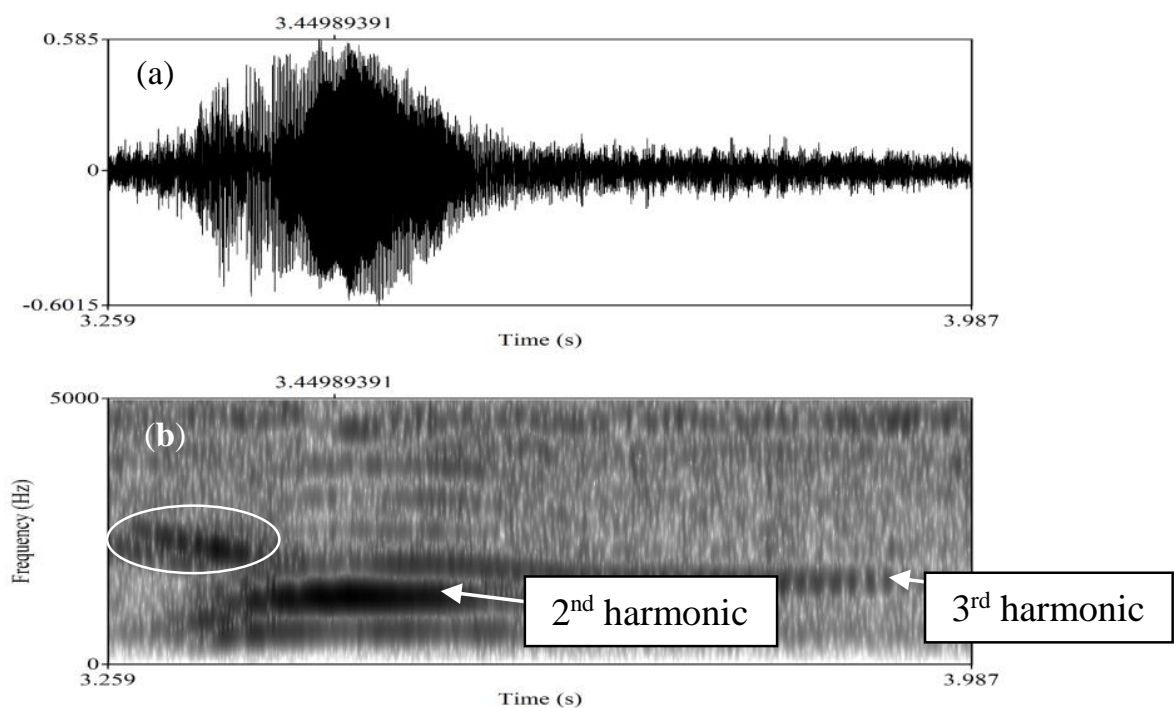

Figure 2. The (a) oscillogram and (b) spectrogram of male $P$. glandulosa respond call towards playback call. The insect sound is as circled.

Eight out of ten male individuals tried to approach the source of the call. However, all of them stopped moving around $15-30 \mathrm{~cm}$ from the playback sources. Some of them even circled around the playback source, as if to determine what makes the advertisement calls (Figure 3 ). The eight males that approached the speaker were located around 1 to $3 \mathrm{~m}$ from the speaker during the playback, and the other two are from 3 to $5 \mathrm{~m}$ from the playback source. Male $P$. glandulosa frogs that are quite distant $(>5 \mathrm{~m})$ from the playback source were also found to respond by producing the same call at the same time as the playback. Both normal playback calls and responds calls is moderate-low pitched of nearly $2 \mathrm{kHz}$. The responsive males were also observed to have enlarged nuptial pad underneath their forearm (Figure 4). During the experiment, there are no simultaneous calling from other nearby male. However, the calls can be heard from afar. 

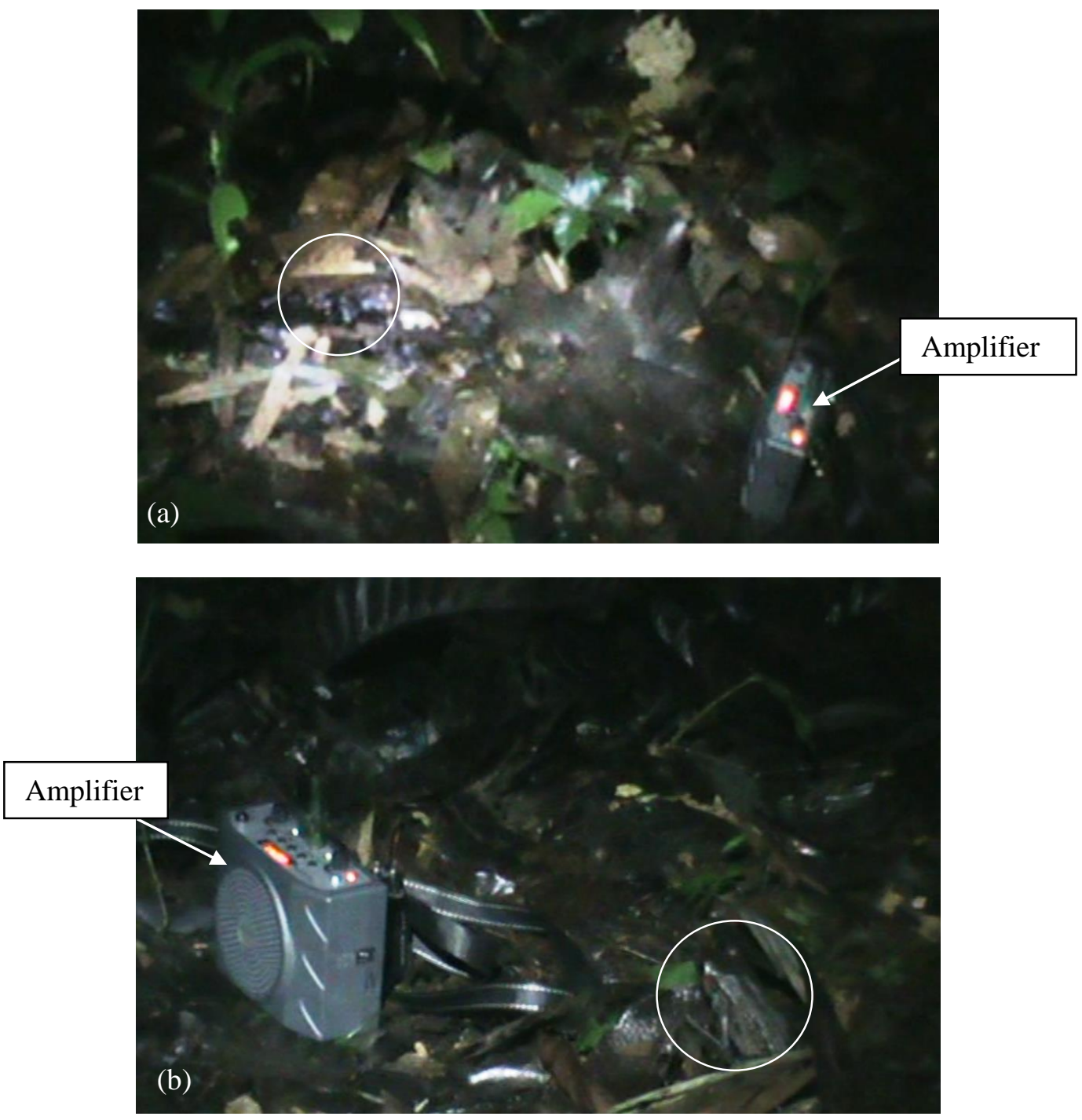

Figure 3. Cropped photo from video shows responsive male P. glandulosa (a) started approaching from the front (circled), and (b) stop moving around $15 \mathrm{~cm}$ and circled around the playback source (circled)

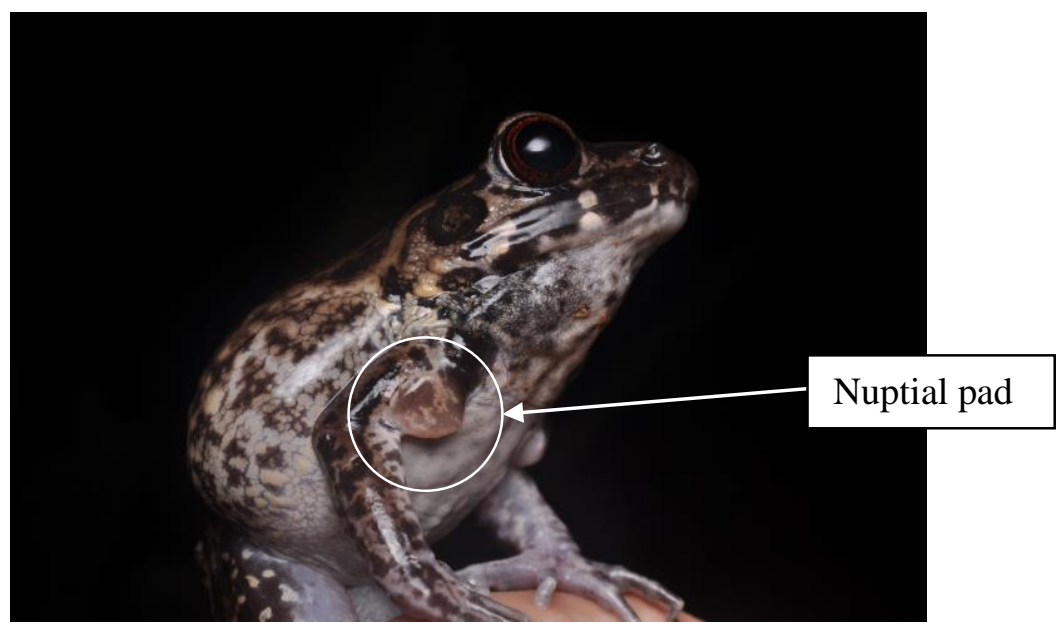

Figure 4. Enlarged nuptial pad (circled) of an active male P. glandulosa 
Meanwhile four females encountered did not respond much except by turning their back on the source of playback. Other two females found responded by producing very soft and short calls. The female responded towards the playback recording by producing a small "wik" sound (Figure 5). Different from male calls, female mating calls are less intense and have shorter duration (Penna et al., 1992; Emerson \& Boyd, 1999). The frequency spectrogram reveals that there is slight frequency modulation, with frequency of $1.75 \mathrm{kHz}$. However, the sound was too weak to be detected and analyzed by Soundruler software, but can be seen in spectrogram in Praat software. All six females are distant from other calling male, where the calls can only be heard from afar.

\section{Acoustic Playback of $P$. baramica (Brown Marsh Frog)}

Figure 6 shows the oscillogram of one note consists of series of pulse of normal $P$. baramica calls that was used for playback recording. Inactive $P$. baramica male frog $(\mathrm{n}=6)$ found alongside trails (distance around $1 \mathrm{~m}$ from speaker) only blinked and did not give much response upon listening to the playback. However, six male $P$. baramica frogs that were calling from some distances $(>5 \mathrm{~m})$ responded to the playback [Figure 6(a)] by producing calls directly after playback calls with increasing number of pulses that ended with tonal note [Figure 6(b)]. Two male $P$. baramica frogs that were calling from around $1 \mathrm{~m}$ responded to the playback similar with male that call from distance, however they approach the playback sources and stopped moving around 15 $\mathrm{cm}$ from it (Figure 7). Female P. baramica frogs (n $=8$ ) were encountered alongside the trails however did not respond to the playback at all. During the experiments, there are no simultaneous calls from other nearby male frogs.

\section{Acoustic Playback of $K$. appendiculatus (Frilled Tree Frog)}

Playbacks for $K$. appendiculatus were done in the environment where the males simultaneously call, with less than $1 \mathrm{~m}$ distance from each other. The distance between playback recording and the target is less than 3 meters. Figure 8 shows the oscillogram of $K$. appendiculatus calls that consists of series of
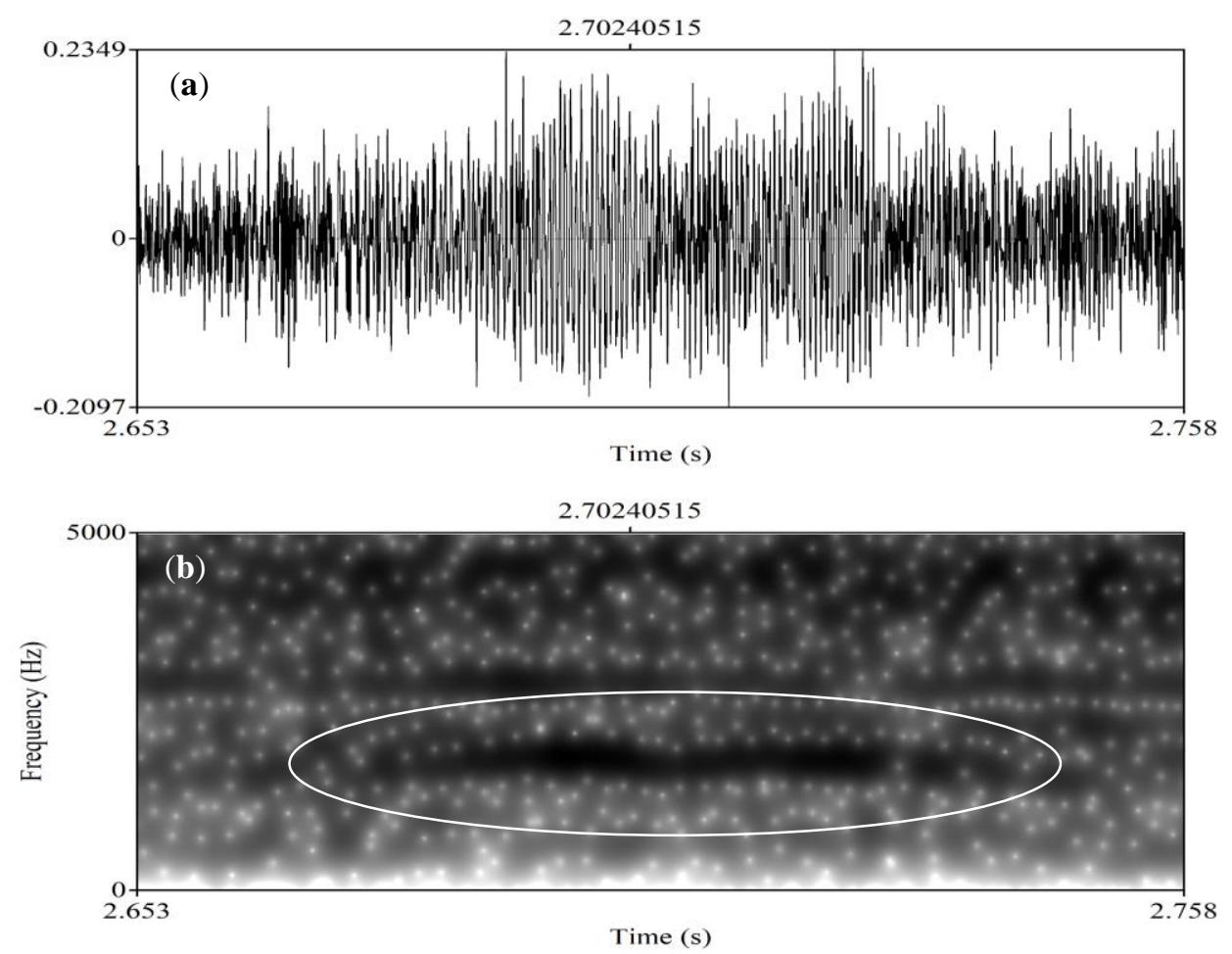

Figure 5. The (a) oscillogram and (b) spectrogram of female P. glandulosa respond call towards playback call (circled) 

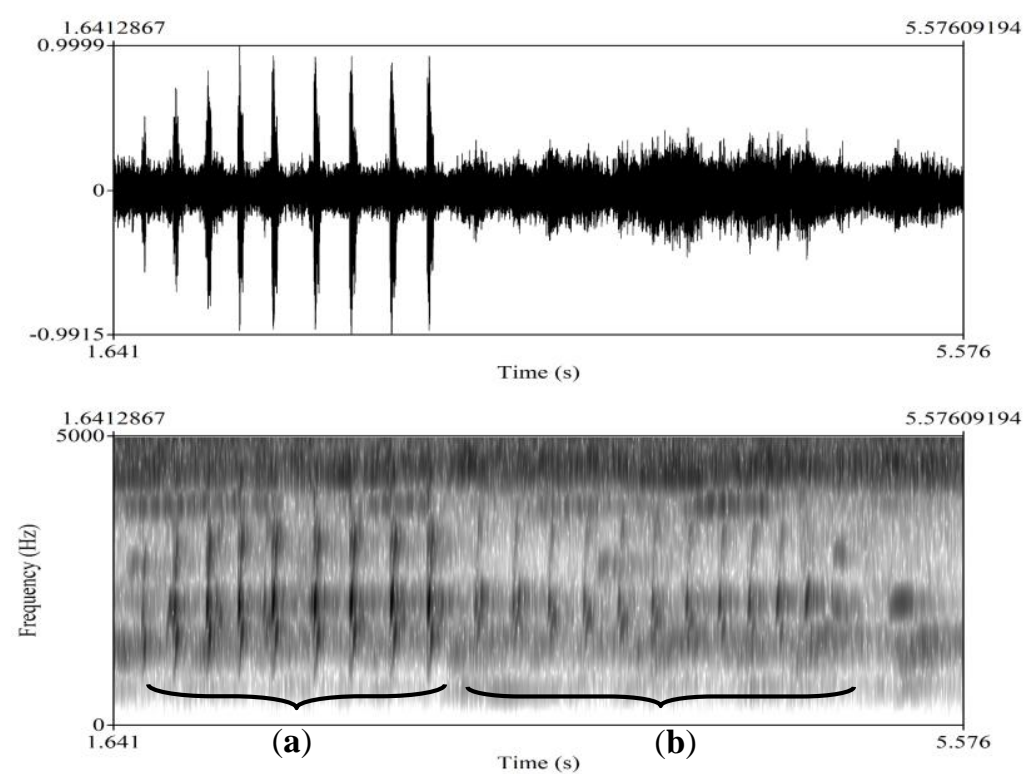

Figure 6. The oscillogram and spectrogram of male $P$. baramica call, showing (a) spectrogram of the playback call and the (b) spectrogram of respond call
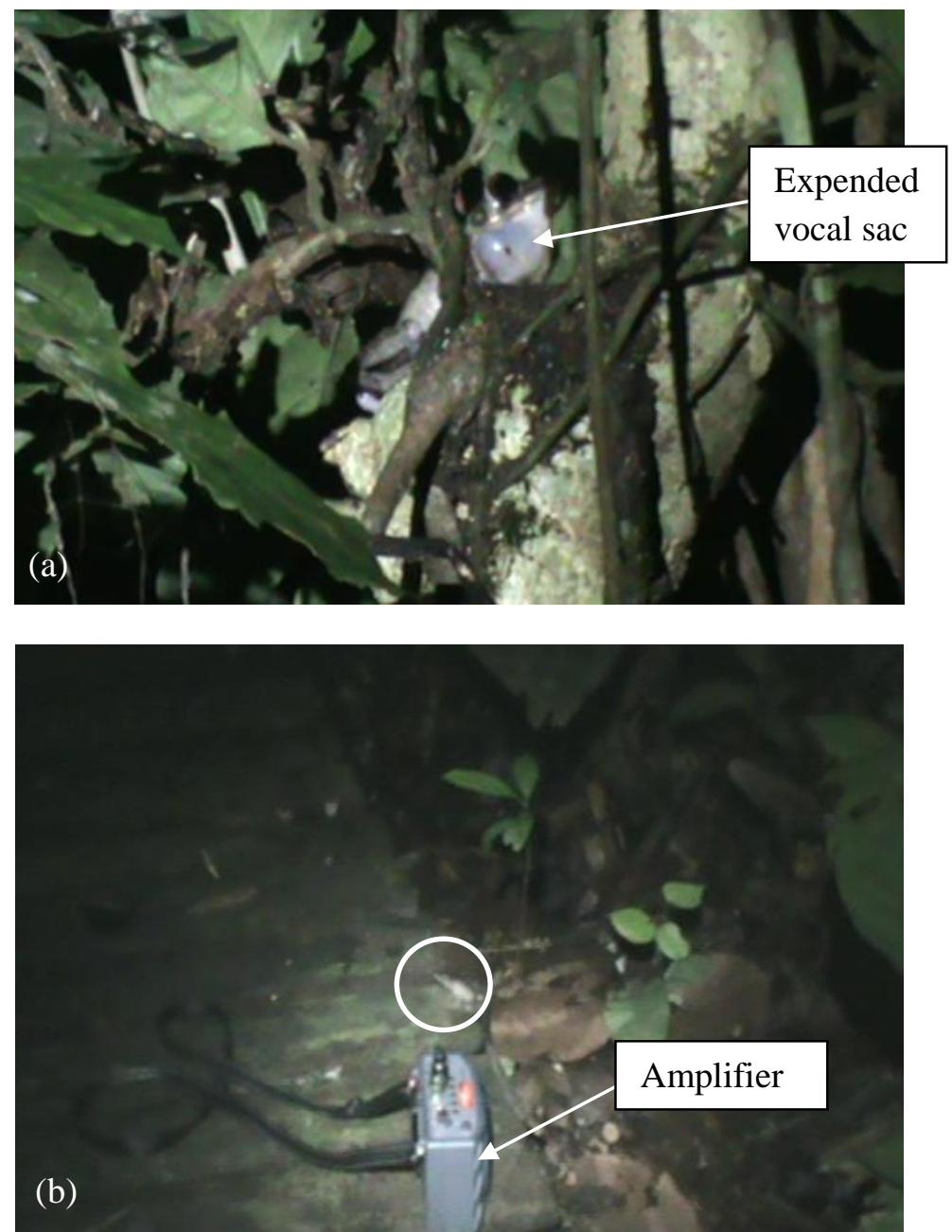

Figure 7. Cropped photo from video shows responsive male P. baramica (a) started calling at the top of the tree, and (b) went down toward playback source and stop moving around $15 \mathrm{~cm}$ from playback sources (circled) 
notes, and was used for playback recording. For male $K$. appendiculatus $(\mathrm{n}=10)$, the individuals responded by stop making calls and start moving towards the sound source. Kurixalus appendiculatus males encountered had responded to the playback by moving their head up and down and make a move towards the amplifier without producing any call to confront the alleged male (Figure 9).

However, no respond call was produced. Compared to $P$. glandulosa, nearby males were not affected by playback calls, only the individuals that the amplifier was directed towards them responded. All three species of $P$. glandulosa, $P$. baramica and $K$. appendiculatus did not come closed enough to knock down the amplifier. It stops around $15-30 \mathrm{~cm}$ from the amplifier but still moving its head around, like to accurately pinpointing the sound source, or confused because there were no intruders when they reached the sound source. As this is call from male to male, this behavior most probably acts as aggression, to warn the intruding male. Female $K$. appendiculatus $(\mathrm{n}=5)$ encountered did not respond to the playback.
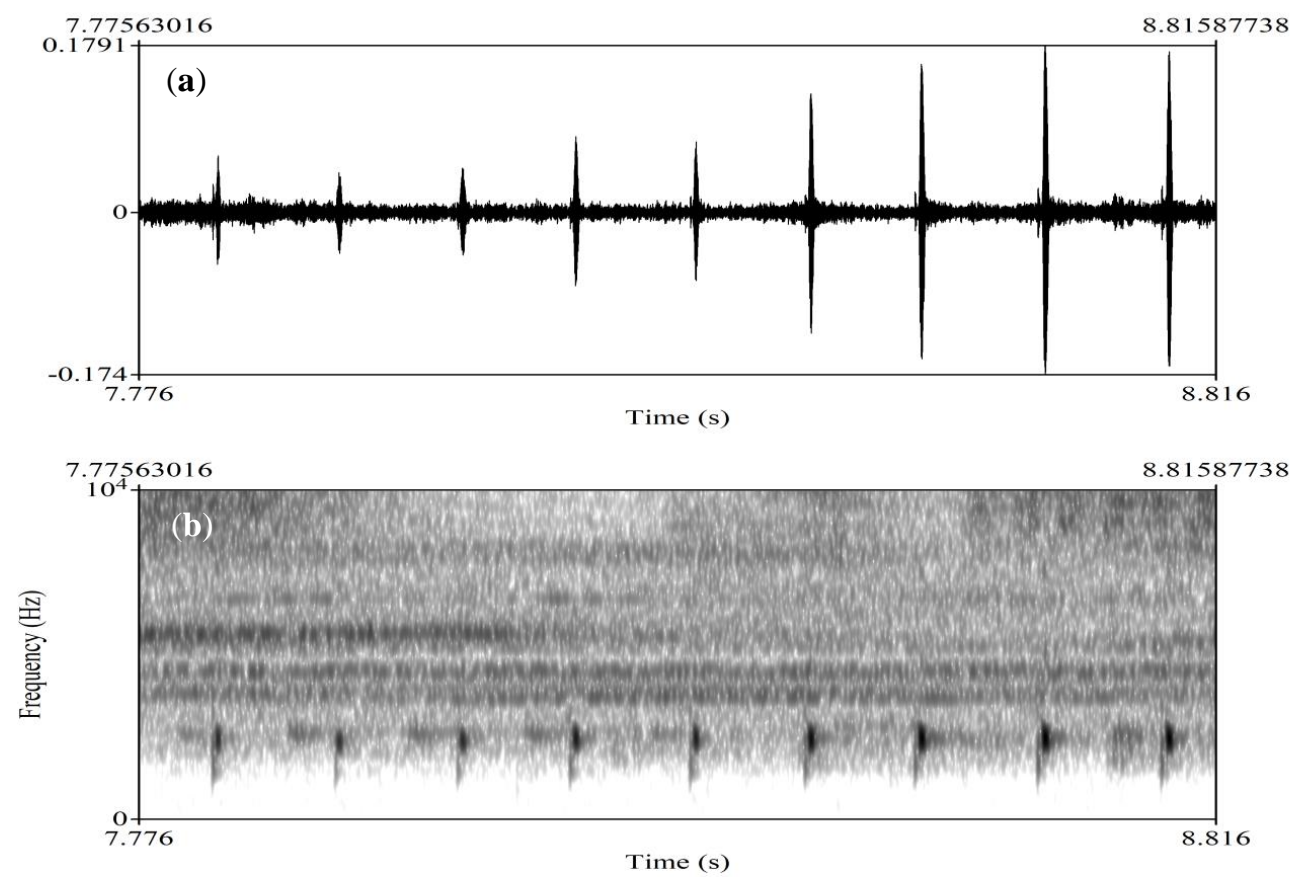

Figure 8. The (a) oscillogram and (b) spectrogram of male K. appendiculatus call

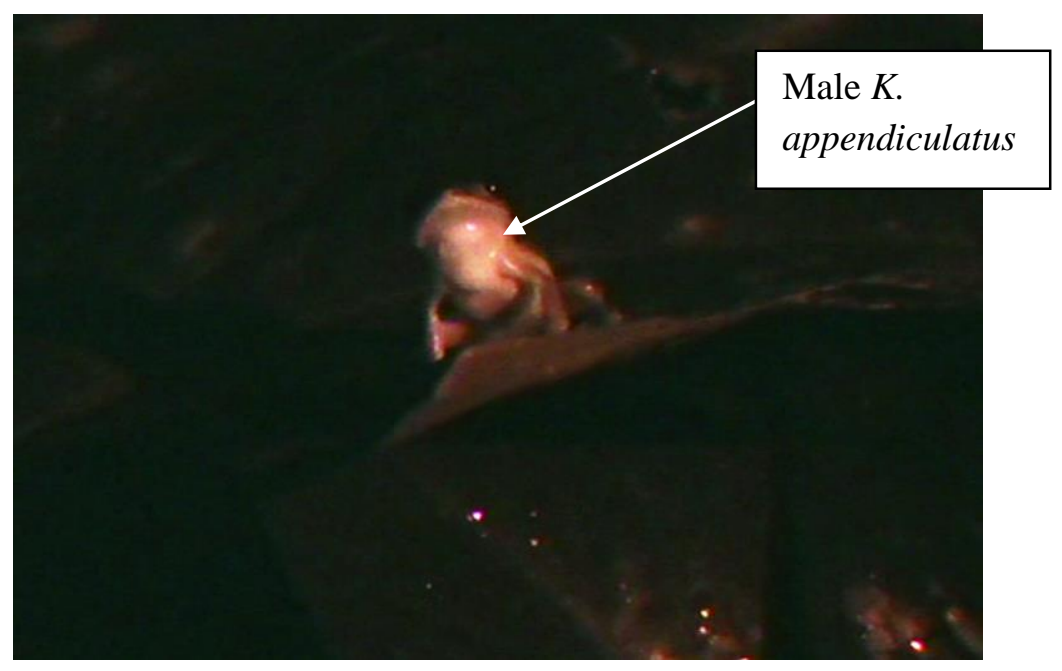

Figure 9. Cropped photo from video shows responsive male $K$. appendiculatus moving their head up and down 


\section{DISCUSSION}

Most of the male frogs do respond by confronting the playback source which is the amplifier and the carrier of the amplifier (Table 1). Only $P$. glandulosa were found to produce aggressive calls towards the playback recording. All male $P$. glandulosa encountered had responded immediately with aggressive calls after they heard the recorded calls. The frogs were probably threatened by the calls of intruding males, and calls were produced as a form of male spacing (Bee, 2007). Males of all three species responded by approaching the playback source, as if they were trying to confront the intruders as the act of aggression. Out of three studied species, only male $K$. appendiculatus were calling near each other, whereas each calling males of $P$. glandulosa and $P$. baramica were distant from one another. During 10 minute-playback recording, responding male were either stop closed to the playback source or jumping around it, as if to examined the foreign object that emitting the calls. The result might differ if there are an actual calling frog instead of speaker and amplifier. After the playback calls were stopped, the responding frogs continued to stay at same place without moving. Narins et al. (2003) reported that the physical attacks by territorial male frogs can be

Table 1. Summary of responses towards intraspesific playback calls.

\begin{tabular}{|c|c|c|c|c|c|}
\hline \multirow[t]{2}{*}{ Species } & \multirow[t]{2}{*}{$\operatorname{Sex}(n)$} & \multirow{2}{*}{$\begin{array}{c}\text { Distance from } \\
\text { Playback Source } \\
(\mathrm{m})\end{array}$} & \multicolumn{3}{|c|}{ Response towards Playback Recording } \\
\hline & & & $\begin{array}{l}\text { Respond by } \\
\text { calling }\end{array}$ & $\begin{array}{l}\text { Respond by } \\
\text { approaching }\end{array}$ & No Respond \\
\hline \multirow{6}{*}{$\begin{array}{l}\text { Pulchrana } \\
\text { glandulosa }\end{array}$} & \multirow[t]{3}{*}{ Male (10) } & $1-3$ & 8 & 8 & 0 \\
\hline & & $3-5$ & 2 & 0 & 0 \\
\hline & & $>5$ & 0 & 0 & 0 \\
\hline & \multirow{3}{*}{$\begin{array}{c}\text { Female } \\
\text { (6) }\end{array}$} & $1-3$ & 2 & 0 & 4 \\
\hline & & $3-5$ & 0 & 0 & 0 \\
\hline & & $>5$ & 0 & 0 & 0 \\
\hline \multirow[t]{6}{*}{ Pulchrana baramica } & \multirow[t]{3}{*}{ Male (14) } & $1-3$ & 2 & 0 & 4 \\
\hline & & $3-5$ & 0 & 0 & 2 \\
\hline & & $>5$ & 6 & 0 & 0 \\
\hline & \multirow{3}{*}{$\begin{array}{c}\text { Female } \\
\text { (8) }\end{array}$} & $1-3$ & 0 & 0 & 8 \\
\hline & & $3-5$ & 0 & 0 & 0 \\
\hline & & $>5$ & 0 & 0 & 0 \\
\hline \multirow{6}{*}{$\begin{array}{l}\text { Kurixalus } \\
\text { appendiculatus }\end{array}$} & \multirow[t]{3}{*}{ Male (10) } & $1-3$ & 0 & 8 & 0 \\
\hline & & $3-5$ & 0 & 0 & 2 \\
\hline & & $>5$ & 0 & 0 & 0 \\
\hline & \multirow{3}{*}{$\begin{array}{c}\text { Female } \\
\text { (3) }\end{array}$} & $1-3$ & 0 & 0 & 3 \\
\hline & & $3-5$ & 0 & 0 & 0 \\
\hline & & $>5$ & 0 & 0 & 0 \\
\hline
\end{tabular}

provoked in response to dynamic bimodal stimuli.

The calls made by responding female $P$. glandulosa need to be further explored since it is unclear whether the responded calls were meant to inform that the male was accepted or rejected for breeding. However, it is known that female frogs most commonly did not initiate the calling, but rather in responds toward the advertisement calls of the male (Orlov, 1997; Tobias et al., 1998). The vocalisation may act as signal to alert the male that they are female and gravid. Characteristics between female calls and the calls of conspecific males were known to be related directly to sexual dimorphisms in laryngeal apparatus morphology (Emerson \& Boyd, 1999).
For $P$. baramica, males that were calling from some distances $(1-5 \mathrm{~m})$ responded to the playback, but the male that are close to the playback source did not respond. For $K$. appendiculatus, unresponsive female to the playback sound might due to the presence of several males in the surrounding that allow it to choose the fittest individual male, where the playback sound might not be the fittest call among them. They might also be "prolonged breeders" (Wells, 1977), where reproduction often takes place in more predictable environments and can occur over a long time period.

Playback of the interspecific calls were also conducted, where calls of male $P$. glandulosa were played to $P$. baramica and $K$. appendiculatus male 
call of $P$. baramica to $K$. appendiculatus and $P$. glandulosa, and male call of $K$. appendiculatus to $P$. glandulosa and $P$. baramica. However, the playback calls illicit no response from the targeted individuals. This probably because they are neighbours, as some territorial animals display low levels of aggression towards a familiar territorial neighbour in its usual territory (Bee \& Gerhadt, 2002). They might have evolved to adapt in a noisy environment such as Bornean rainforest, by enhancing their ability to select biologically relevant sounds from background noise, such as the calls of other species (Narins, 1982).

\section{CONCLUSION}

From the acoustic playback, both male and female $P$. glandulosa responded towards the calls. The male produces a crying-like sound meanwhile the female produces a small "wik" sound. For male $K$. appendiculatus, the individuals responded by moving towards the sound source. The results showed that regardless of sex, frogs reacted differently towards their recorded vocalization. Advertisement call recorded can only be recognized by the conspecific frogs after aired on the amplifier. This shows that a frog possesses a capacity for call recognition from acoustic playback. The sound recorded thus was good enough to be used for future research and amphibian conservation management.

\section{ACKNOWLEDGEMENTS}

This study was funded by Ministry of Higher Education (MoHE) research grant FRGS/1/2013/STWN10/UNIMAS/02/3 and F07(DPP44)/1264/2015(19). Special thanks to the Forestry Department of Sarawak for the permit given NCCD907.4.4 (Jld.12)-106; No.236/2015) to collect sample for this study.

\section{REFERENCES}

Amézquita, A., Castellanos, L. \& Hodl, W. (2005). Auditory matching of male Epipedobates femoralis (Anura: Dendrobatidae) under field conditions. Animal Behaviour, 70: 1377-1386.

Amram, M.F., Zainudin, R. \& Abdul Wahid, H. (2018). Mating calls of selected Sarawak toads (Amphibia: Anura: Bufonidae). Sains Malaysiana, 47(1): 1-7.

Bee, M.A. (2007). Selective phonotaxis by male wood frogs (Rana sylvatica) to the sound of a chorus. Behavioral Ecology and Sociobiology, 61(6): 955966.

Bee, M.A. \& Gerhardt, H.C. (2002). Individual voice recognition in a territorial frog (Rana catesbeiana). Proccedings of the Royal Society B Biological Sciences, 269: 1443-1448.

Bee, M.A., Perrill, S.A. \& Owen, P.C. (1999). Size assessment in simulated territorial encounters between male green frogs (Rana clamitans). Behavioral Ecology and Sociobiology, 45: 177-184.

Bee, M.A., Perrill, S.A. \& Owen, P.C. (2000). Male green frogs lower the pitch of acoustic signals in defense of territories: a possible dishonest signal of size? Behavioral Ecology, 11(2): 169-177.

Emerson, S.B. \& Boyd, S.K. (1999). Mating variations of female frogs: Control and Evolutionary Mechanisms. Brain Behavior and Evolution, 53(4): 187-197.

Gridi-Papp, M. (2003-2007). SoundRuler Acoustic Analysisver 0.9.6.0. http://soundruler.sourceforge.net.

Inger, R.F. \& Stuebing, R.B. (2005). A field guide to the frogs of Borneo. Kota Kinabalu: Natural History Publication (Borneo) Sdn. Bhd.

Lendvai, A.Z., Akcay, C., Weiss, T., Haussmann, M.F., Moore, I.T. \& Bonier, F. (2015). Low cost audiovisual playback and recording triggered by radio frequency identification using Raspberry Pi. PeerJ, 3(4): 877.

Lima, A.P., Simoes, P.I. \& Kaefer, I.L. (2014). A new species of Allobates (Anura: Aromobatidae) from the Tapajos River basin, Para State, Brazil. Zootaxa, 2889(3): 355-387.

Marshall, V.T., Humfeld, S.C. \& Bee, M.A. (2003). Plasticity of aggressive signalling and its evolution in male spring peepers, Pseudacris crucifer. Animal Behaviour, 65(6): 1223-1234.

Narins, P.M. (1982) Effects of masking noise on evoked calling in the Puerto Riean Coqui (Anura: Leptodactylidae). Journal of Comparative Physiology, 147(4): 439-446.

Narins, P.M., Hödl, W. \& Grabul, D.S. (2003). Bimodal signal requisite for agonistic behavior in a dart-poison frog, Epipedobates femoralis. Proceedings of the National Academy of Sciences, 100(2): 577-580.

Orlov, N. (1997). Breeding behavior and nest construction in a Vietnam frog related to Rana blythi. Copeia, 1997(2): 464-465. 
Penna, M., Capranica, R.R. \& Somers, J. (1992). Hormone-induced vocal behavior and midbrain auditory sensitivity in the green tree frog, Hyla cinerea. Journal of Comparative Physiology A, 170(1): 73-82.

Preininger, D., Boeckle, M., Freudmann, A., Starnberger, I., Sztatecsny, M. \& Hödl, W. (2013). Multimodal signaling in the small torrent frog (Micrixalus saxicola) in a complex acoustic environment. Behavioral Ecology and Sociobiology, 67(9): 1449-1456.

Reichert, M.S. (2013). Visual cues elicit courtship signals in a nocturnal anuran. Behavioral Ecology and Sociobiology, 67(2): 265-271.

Santana, D.J., Magalhaes, F.de M., Sao Pedro, V. deA., Mangia, S., Amado, T.F. \& Garda, A.A. (2016). Calls and tadpoles of the species of Pseudis (Anura, Hylidae, Pseudae). Herpetological Journal, 26(2): 139-151.
Tobias, M.L., Tomasson, J. \& Kelley, D.B. (1998). Attaining and maintaining strong vocal synapses in female Xenopus laevis. Journal of Neurobiology, 37: 441-448.

Wells, K.D. (1977). The social behavior of anuran amphibians. Animal Behaviour, 25(3): 666-693.

Zainudin, R., Rahman, M.A., Md-Zain, B.M., Nor, S.M., Norhayati, A. \& Inger, R.F. (2009). Ciri-ciri panggilan katak Borneo (Genus: Hylarana) dari populasi Sarawak, Malaysia Timur. Sains Malaysiana, 38(5): 619-624.

Zainudin, R., Rahman, M.A. \& Md-Zain, B.M. (2010). Mating calls description of five species of frogs from the genus Hylarana Tschudi 1838 (Amphibia, Anura, Ranidae) from Sarawak, Malaysia. Sains Malaysiana, 39(3): 363-369. 